\title{
Relationship between sulfur speciation in soils and plant availability
}

\author{
Xiao-Quan Shan*, Bin Chen, Tian-Hong Zhang, Fu-Liang Li, \\ Bei Wen, Jin Qian \\ Research Center for Eco-Environmental Sciences, Chinese Academy of Sciences, PO Box 2871, Beijing 100085, China
}

Received 23 October 1996; accepted 7 February 1997

\begin{abstract}
Both pot experiments and field survey were conducted to investigate the relationship between sulfur speciation in soils and sulfur concentration in plants. Soil sulfur was fractionated into water-soluble sulfate $\left(\mathrm{S}_{1}\right)$, adsorbed sulfate $\left(S_{2}\right)$, carbonate-occluded sulfate $\left(S_{3}\right)$, ester sulfate $\left(S_{4}\right)$ and carbon-bonded sulfur $\left(S_{5}\right)$. The correlation was well described by multiple linear regression equations with plant sulfur concentration being the dependent variable and soil sulfur species being the independent variable. All the correlations were found to be highly significant $(P<0.01)$. Moreover, the regression equations show consistent forms with respect to the relative magnitude of the factors before each of the variables, by the order $S_{1}>S_{2}>S_{4}>S_{5}>S_{3}$. The average values of the factors before $S_{1}, S_{2}, S_{4}$, $S_{5}$ and $S_{3}$ were $28.6,11.0,3.2,0.47$ and -0.14 , respectively, indicating that water-soluble sulfate was the most easily available form of soil sulfur, followed by adsorbed sulfate, ester sulfate, carbon-bonded sulfur and carbonate-occluded sulfate. Changes in concentrations of the different forms of soil sulfur after pot experiments gave direct evidence to the order of availability. $S_{1}$ and $S_{2}$ decreased significantly, the content of $S_{4}$ also reduced, whereas $S_{5}$ and $S_{3}$ remained almost unchanged. These results suggested that water-soluble and adsorbed sulfate are directly available to plants, while the mineralization of sulfate from organic sulfur, especially from ester sulfate, also made an important contribution to plant uptake of sulfur. It appears that the sum of water-soluble sulfate, adsorbed sulfate and ester sulfate covers most of the available sulfur in soils and can be used as an indicator of the status of soil sulfur. Based on the above consideration a simplified speciation method was recommended to determine the available forms of soil sulfur. (C) 1997 Elsevier Science B.V.
\end{abstract}

Keywords: Sulfur speciation; Soil; Pot experiment and field survey; Multiple linear regression; Plant availability

\section{Introduction}

The increasing incidence of sulfur deficiency throughout the world has focused attention on

\footnotetext{
*Corresponding author. Fax: +86 $1062923563,+8610$ 62918177.
}

the ways of assessing sulfur status in soils (Fox et al., 1964; Ensminger and Freney, 1966; Scott, 1981). Numerous methods have been proposed to evaluate the amounts of soil sulfur available for plant uptake. These methods generally involve extraction of soil sulfur with a weak salt solution such as $\mathrm{CaCl}_{2}, \mathrm{Ca}\left(\mathrm{H}_{2} \mathrm{PO}_{4}\right)_{2}$ and $\mathrm{NaHCO}_{3}$. 
Great efforts have been devoted to the sulfur speciation analysis in soils due to the need to study sulfur dynamics and bio-geochemistry, and detailed information on sulfur spcciation has been obtained (Landerst et al., 1983; Nriagu and Soon, 1985; Shan et al., 1992; Shan and Chen, 1995). Soil inorganic sulfur may occur as sulfate, sulphide, pyrite as well as elemental sulfur, while soil organic sulfur was divided into two distinct groups: ester sulfate and carbon-bonded sulfur. Traditionally, ester sulfate and carbon-bonded sulfur were determined by difference method, which may suffer from large errors due to incomplete estimation of soil inorganic sulfur. Recently, Shan and Chen (1995) proposed a method for direct determination of carbon-bonded sulfur. Moreover, a substantial amount of inorganic sulfate may be occluded in carbonate minerals in calcareous soils which can be released by dilute $\mathrm{HCl}$ extraction, this finding will also reduce the error present in the previous ester-sulfate determination methods (Chen and Shan, submitted).

It is well recognized that the capacity of a soil to supply plant available sulfur depends on both the amount and the availability of the various inorganic and organic forms of soil sulfur. It is believed that water-soluble and adsorbed sulfate is readily available to plants (Ensminger and Freney, 1966). However, the small amounts of the available sulfate present in most surface soils indicate that there must be other sources of available sulfur to meet the requirement of plant growth. Mineralization of soil organic sulfur is considered to play an important role in maintaining the sulfur nutrition of intensively-grown crops in soils and many studies have been carried out to investigate the potential and mechanism of organic sulfur mineralization. David et al. (1983) reported rapid mineralization of organic sulfur in a forest soil. McLaren et al. (1985) also found that there was a continuous, concurrent mineralization and immobilization cycle taking place involving a proportion of the soil organic sulfur pool. A dynamic study (N'dayegamiye et al., 1994) revealed that the cumulative sulfur mineralization (Sm) was linear with time and total sulfur uptake of alfalfa was strongly correlated to $\mathrm{Sm}(r=$ $\left.0.81^{* *}\right)$. A recent review of soil sulfur testing (Anderson et al., 1992) concluded that soil extraction methods which included a fraction of organic sulfur along with inorganic sulfate correlated best with soil sulfur availability to pastures.

Blair et al. (1994) pointed out that for a soil test to be effective it must sample pools of sulfur that are immediately available to the plant and organic pools that turn over rapidly and supply sulfur in the longer term. However, the traditional soil testing methods did not pay much attention to the relationship between sulfur speciation in soils and plant availability. Sulfur in the soil testing extracts was a mixture of inorganic and organic sulfur (Tan et al., 1994; Zhao and McGrath, 1994), and the roles of different sulfur forms cannot be identified. As a result, the correlations between soil sulfur testing and plant uptake of sulfur were often found to be poor (Jones et al., 1972; Hoque et al., 1987; Haneklaus et al., 1995).

The aim of the present study is to investigate the relationship between chemical speciation of sulfur in soil and plant availability. Both pot experiments and field survey were conducted. The results of sulfur speciation analysis were correlated with plant sulfur content using single and multiple linear regression analysis, which is widely employed in the study of plant availability of soil elements (Randall et al., 1976; Qian et al., 1995).

\section{Materials and methods}

\subsection{Soils}

The 13 soil samples used for pot-culture experiments were collected from different rural regions of China, representing a range of chemical and physical properties. They are all from cultivated soils and the samples were taken from the surface layer $(0-20 \mathrm{~cm})$. The soils were air-dried, ground and passed through a 2-mm sieve to remove rocks, roots and other larger particles. For the laboratory analyses a representative $7-\mathrm{kg}$ subsample of each soil was used for preparation for a pot-culture experiment. The properties of the soils were given previously (Qian et al., 1995). The soils 
collected from field survey are of similar properties. They all belong to Mollisol and have a relatively high $\mathrm{pH}(7.5-8.2)$.

\subsection{Pot-culture experiments}

The air-dried soil samples were placed in plastic-lined pots $(1000 \mathrm{~g} /$ pot $)$ and planted with spring wheat (Triticum aestivum $L$.) and rape ( $B$. chinensis) under greenhouse conditions. A randomized complete block design consisting of three replicates was used. Wheat and rape were planted at 15 and 20 seeds per pot and subsequently thinned to 10 plants. The pots received supplementary fertilization with a $\mathrm{NH}_{4} \mathrm{NO}_{3}-\mathrm{KH}_{2} \mathrm{PO}_{4}$ solution supplying 20,20 and $30 \mathrm{mg}$ /pot of elemental $\mathrm{N}$, $P$, and $K$, respectively. The soils were initially adjusted to approximately $60 \%$ water-holding capacity, and losses from evapotranspiration were made up by daily watering with de-ionized water.

The above-ground parts of the plants were harvested 60 days after planting. The harvested plant samples were washed with de-ionized water, dried at $60^{\circ} \mathrm{C}$ for $48 \mathrm{~h}$ and ground in an agate mortar and pestle to pass through a $0.85-\mathrm{mm}$ ( 20 -mesh) sieve. Plant analysis for sulfur was accomplished by digesting a portion of dried, ground sample $(0.500 \mathrm{~g})$ in a $3: 1$ mixture of $\mathrm{HNO}_{3}$ and $\mathrm{HClO}_{4}(5$ $\mathrm{ml})$.

\subsection{Field survey}

Most availability studies were conducted in pot experiments due to its advantage of easy controlling of experimental conditions. However, the pot experiments do not simulate well the real situation of crop growth in the field conditions and the results obtained from pot experiments cannot be extended to agricultural practice without further testing. Thercfore in this study, in addition to pot experiments, field survey was carried out in the surrounding area of Beijing. Ripe rice (Oryza sativa) and corn (Zea mays) were collected from 13 and 12 different sites, respectively, on October 4, 1995, just prior to harvest. The sampling sites all located in the suburb of Beijing, and can be encompassed in a circle centered in $39^{\circ} 52^{\prime} \mathrm{N}, 116^{\circ} 20^{\prime} \mathrm{E}$, with a radius of 50 $\mathrm{km}$. The region belongs to temperate zone and continental monsoon climate characterized by a cold, windy and arid winter and a hot, rainy summer. Rice and corn are principal autumn crops in this area.

At each sampling site, three intact plants of rice or corn were dug out with a lump of soil (of about $15 \times 15 \times 15 \mathrm{~cm}^{3}$ ) remaining around the roots. Soil was taken from between the roots of the plants. The soils were air-died, ground and passed through a $0.85-\mathrm{mm}$ (20-mesh) sieve. Roots, stems, leaves and seeds of the plants were separated and washed with de-ionized water. Plant materials was dried, ground and analyzed for sulfur as described in the pot experiment section.

\subsection{Procedure for sulfur speciation analysis}

Because the reduced forms of inorganic sulfur cannot be detected in most of the soils used in this study, only water-soluble sulfate, adsorbed sulfate, carbonate-occluded sulfate, ester sulfate and carbon-bonded sulfur were determined. The procedure was schematically shown in Fig. 1. Details of the methods were given below.

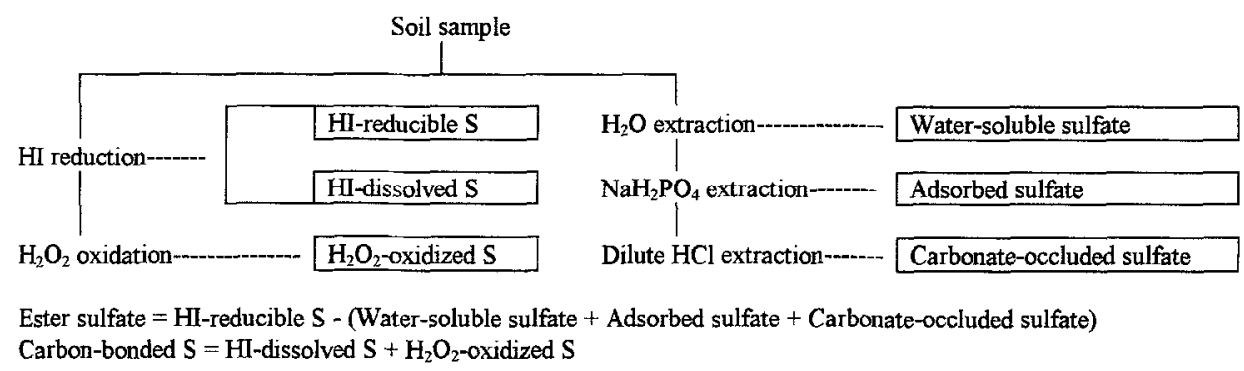

Fig. 1. Schematic diagram for the determination of different sulfur forms in soils. 


\subsubsection{Water-soluble sulfate}

An accurately weighed soil sample $(1.00 \mathrm{~g})$ was transferred to a 50-ml centrifuge tube. De-ionized water $(10 \mathrm{ml})$ was added. The mixture was shaken on a reciprocal shaker for $30 \mathrm{~min}$. The resulting suspensions was centrifuged at $10000 \mathrm{rev} . / \mathrm{min}$ for $10 \mathrm{~min}$. The supernatant was transferred as complete as possible to $10-\mathrm{ml}$ volumetric flask without disturbing the solid at the bottom of the centrifuge tube.

\subsubsection{Adsorbed sulfate}

The residual soil in the centrifuge tube was rinsed with $5 \mathrm{ml}$ of de-ionized water which was discarded after centrifugation. Then $10 \mathrm{ml}$ of $0.032 \mathrm{M} \mathrm{NaH}_{2} \mathrm{PO}_{4}$ was added into the tube. The tube was shaken for $30 \mathrm{~min}$ and centrifuged at $10000 \mathrm{rev} . / \mathrm{min}$ for $10 \mathrm{~min}$ to get the supernatant.

\subsubsection{Carbonate-occluded sulfate}

The residual soil from above step was rinsed with de-ionized water as described above. Then $20 \mathrm{ml}$ of $1 \mathrm{~N} \mathrm{HCl}$ was added to the centrifuge tube. Because the $\mathrm{HCl}$-extraction was a gas-yielding (mainly $\mathrm{CO}_{2}$ ) procedure, the centrifuge tube was placed upward on the shaker and covered with a lid bearing a small hole. The hole was pierced by a needle to release the gas produced but was small enough to prevent any leaking of the solution in the tube. The shaking was continued for $1 \mathrm{~h}$ followed by centrifugation to get the supernatant.

\subsubsection{Ester sulfate and carbon-bonded sulfur}

A subsample was taken and subjected to the $\mathrm{HI}$ reduction and $\mathrm{H}_{2} \mathrm{O}_{2}$ oxidation sequentially as described by Shan and Chen (1995). Because the reduced form of inorganic sulfur was not detected, ester sulfate was estimated by subtracting water-soluble sulfate, adsorbed sulfate and carbonate-occluded sulfate from HI-reducible sulfur and carbon-bonded sulfur by summing HI-dissolved sulfur and $\mathrm{H}_{2} \mathrm{O}_{2}$-oxidized sulfur.

\subsection{Determination of sulfur by ion chromatography}

(IC) and inductively coupled plasma-atomic

emission spectroscopy (ICP-AES)

Because both inorganic and organic sulfur may be extracted by water, $\mathrm{NaH}_{2} \mathrm{PO}_{4}$, and dilute $\mathrm{HCl}$, sulfate in these extracts was determined by IC (Dionex 2000i) due to its sensitivity and specificity to inorganic sulfate (Shan et al., 1992; Zhao and McGrath, 1994). Sulfur recovered by $\mathrm{HI}$ reduction and $\mathrm{H}_{2} \mathrm{O}_{2}$ oxidation were determined by ICP-AES (Jarrel-Ash model $1155 \mathrm{~V}$ polychromator). The operating conditions were given previously (Shan et al., 1991).

\section{Results and discussion}

\subsection{Correlation between sulfur speciation in soils and sulfur concentration in plants}

The ranges and mean values of different sulfur fractions in the soils and sulfur concentration in the plants are presented in Table 1 . Soils were divided into two groups: soils used in pot experiments and soils collected from field survey. Water-soluble sulfate, adsorbed sulfate, carbonateoccluded sulfate, ester sulfate and carbon-bonded sulfur were designated as $S_{1}, S_{2}, S_{3}, S_{4}$ and $S_{5}$, respectively for the convenience of discussion. The mean values of $S_{1}$ for the two soil groups was similar (13.1 and $14.2 \mathrm{mg} / \mathrm{g}$, respectively). However, much more $S_{2}$ was found in the pot experiment soils than in the field survey soils, with the mean of the former being $57.4 \mathrm{mg} / \mathrm{g}$, and the latter $19.6 \mathrm{mg} / \mathrm{g}$. The reason is obvious: seven of the 13 potted soils were collected from subtropical zoncs, rich in $\mathrm{Fe}-\mathrm{Al}$ oxides, which are responsible for sulfate adsorption (Johnson and Todd, 1983; Stanko-Golden et al., 1994). $S_{3}$ is an important fraction for both soil groups and its content often surpasses the sum of $S_{1}$ and $S_{2}$. The amount of $S_{3}$ was found to be closely related to the content of carbonate minerals in soils $(r=$ $0.986^{* * *}, n=30$ ), indicating $\mathrm{S}_{3}$ is most likely to be occluded in carbonates in calcareous soils. 
Table 1

Ranges and means of different sulfur forms in soils and plant sulfur concentrations $(\mu \mathrm{g} / \mathrm{g})$

\begin{tabular}{|c|c|c|c|c|c|c|c|c|}
\hline \multirow[b]{2}{*}{ Soil S } & & \multicolumn{3}{|c|}{ Pot experiments ( 13 soils) } & \multicolumn{3}{|c|}{ Field survey (25 soils) } & \\
\hline & & \multicolumn{2}{|l|}{ Range } & Mean & \multicolumn{2}{|c|}{ Range } & \multicolumn{2}{|c|}{ Mean } \\
\hline $\mathbf{S}_{1}$ & & $5.8-44.4$ & & 13.1 & \multicolumn{2}{|c|}{$8.0-34.2$} & \multicolumn{2}{|c|}{14.2} \\
\hline $\mathrm{S}_{2}$ & & $5.2-176$ & & 57.4 & \multicolumn{2}{|c|}{$11.5-29.7$} & \multicolumn{2}{|c|}{19.6} \\
\hline $\mathrm{S}_{3}$ & & $5.5-784$ & & 155 & \multicolumn{2}{|c|}{$34.8-513.6$} & \multicolumn{2}{|c|}{169.8} \\
\hline $\mathrm{S}_{4}$ & & $41.0-205$ & & 133.9 & & 209.9 & \multicolumn{2}{|c|}{87.3} \\
\hline \multirow[t]{2}{*}{$\mathrm{S}_{5}$} & & $60.4-1041$ & & 391.8 & \multicolumn{2}{|c|}{$60.9-274.1$} & \multicolumn{2}{|c|}{144.4} \\
\hline & Wheat & & Rape & & Corn & & Rice & \\
\hline Plant S & $\overline{\text { Range }}$ & Mean & Range & Mean & Range & Mean & Range & Mean \\
\hline Shoot & $689-1583$ & 1161 & $947-2027$ & 1470 & & & & \\
\hline Root & & & & & $1556-2265$ & 1800 & $1570-2837$ & 2212 \\
\hline Stem & & & & & $282-880$ & 491 & $570-1857$ & 1146 \\
\hline Leaf & & & & & $1872-2837$ & 2292 & $1150-2220$ & 1653 \\
\hline Seed & & & & & $865-1207$ & 1012 & $1038-1456$ & 1246 \\
\hline
\end{tabular}

Abbreviations: $\mathrm{S}_{1}$, water-soluble sulfate; $\mathrm{S}_{2}$, adsorbed sulfate; $\mathrm{S}_{3}$, carbonate-occluded sulfate; $\mathrm{S}_{4}$, ester sulfate; $\mathrm{S}_{5}$, carbon-bonded sulfur.

Table 2

Single regression equations between sulfur speciation in soils and sulfur content in wheat and rape (pot experiments, $n=13$ )

Regression equation

\section{Wheat}

$Y_{\mathrm{W}}=623.8+30.79 \mathrm{~S}_{1}$

$Y_{\mathrm{W}}=459.2+10.23 \mathrm{~S}_{1+2}$

$Y_{\mathrm{W}}=296.5+4.18 \mathrm{~S}_{1+2+4}$

$Y_{\mathrm{W}}=626.4+0.97 \mathrm{~S}_{1+2+4+5}$

$Y_{\mathrm{W}}=591.1+1.01 \mathrm{~S}_{1+2+3+4+5}$

Rape

$Y_{\mathrm{R}}=890.2+34.0 \mathrm{~S}_{1}$

$Y_{\mathrm{R}}=622.2+14.23 \mathrm{~S}_{1+2}$

$Y_{\mathrm{R}}=733.7+5.12 \mathrm{~S}_{1+2+4}$

$Y_{\mathrm{R}}=1070+0.71 \mathrm{~S}_{1+2+4+5}$

$Y_{\mathrm{R}}=1029+0.58 \mathrm{~S}_{1+2+3+4+5}$

Abbreviations: as per Table 1.

* Significant at 5\% level.

** Significant at $1 \%$ level.

$* * *$ Significant at $0.1 \%$ level.

Organic sulfur accounted for more than $50 \%$ of total sulfur for most of the soils, with $\mathrm{S}_{5}$ being the major and $\mathrm{S}_{4}$ being the minor fraction. Sulfur concentrations in the plants showed large variations among different crops and among different parts of the same crop. In pot experiments, rape absorbed more sulfur than wheat. Under field conditions the distribution of sulfur among roots, stems, leaves and seeds are similar for corn and rice, with more sulfur accumulated in the roots and leaves, and less sulfur in the stems. These results indicate that if plant analysis is employed to diagnose the status of soil sulfur, it is necessary to standardize the part of the plant to be analyzed and establish different critical values for different plants (Ensminger and Freney, 1966).

Both single and multiple linear regression analysis were performed to assess the relationship between sulfur speciation in soils and plant sulfur concentrations. To find the most suitable regression equation, plant sulfur was correlated with $S_{1}$, $\mathrm{S}_{1}+\mathrm{S}_{2}, \mathrm{~S}_{1}+\mathrm{S}_{2}+\mathrm{S}_{4}, \mathrm{~S}_{1}+\mathrm{S}_{2}+\mathrm{S}_{4}+\mathrm{S}_{5}$ and $\mathrm{S}_{1}+$ $\mathrm{S}_{2}+\mathrm{S}_{3}+\mathrm{S}_{4}+\mathrm{S}_{5}$ (designated as $\mathrm{S}_{1+2}, \mathrm{~S}_{1+2+4}$, $\mathrm{S}_{1+2+4+5}$, and $\mathrm{S}_{1+2+3+4+5}$ ), respectively, for the single regression analysis. The multiple regression was done in a similar way from two-variable regression $\left(S_{1}\right.$ and $\left.S_{2}\right)$ to all five sulfur fractions. The results are given in Tables 1-8.

\subsubsection{Single regression analysis}

In pot experiments, significant correlations ( $P$ $<0.05$ ) were found between sulfur content in wheat and $S_{1}, S_{1+2}$, and $S_{1+2+4}$. However, the correlation coefficient was greatly reduced when 
Table 3

Single regression equations between sulfur speciation in soils and sulfur content in corn (field survey, $n=12$ )

\begin{tabular}{|c|c|}
\hline Regression equation & $r$ \\
\hline \multicolumn{2}{|l|}{ Root } \\
\hline$Y_{\mathrm{Cr}}=1544+29.94 \mathrm{~S}_{1}$ & $0.667^{*}$ \\
\hline$Y_{\mathrm{Cr}}=1442+18.32 \mathrm{~S}_{1+2}$ & $0.692^{* *}$ \\
\hline$Y_{C r}=1279+4.90 S_{1+2+4}$ & $0.736^{* *}$ \\
\hline$Y_{\mathrm{Cr}}=1323+2.26 \mathrm{~S}_{1+2+4+5}$ & $0.605^{*}$ \\
\hline$Y_{\mathrm{Cr}}=1271+1.54 \mathrm{~S}_{1+2+3+4+5}$ & $0.569^{*}$ \\
\hline \multicolumn{2}{|l|}{ Stem } \\
\hline$Y_{\mathrm{Cs}}=293.9+17.65 \mathrm{~S}_{1}$ & $0.658^{*}$ \\
\hline$Y_{\mathrm{Cs}}=227.3+10.20 \mathrm{~S}_{1+2}$ & $0.666^{*}$ \\
\hline$Y_{\mathrm{Cs}}=77.5+3.51 \mathrm{~S}_{1+2+4}$ & $0.606^{*}$ \\
\hline$Y_{\mathrm{Cs}}=81.2+1.95 \mathrm{~S}_{1+2+4+5}$ & 0.530 \\
\hline$Y_{\mathrm{Cs}}=85.0+1.20 \mathrm{~S}_{1+2+3+4+5}$ & $0.555^{*}$ \\
\hline \multicolumn{2}{|l|}{ Leaf } \\
\hline$Y_{\mathrm{Cl}}=1587+41.86 \mathrm{~S}_{1}$ & $0.610^{*}$ \\
\hline$Y_{\mathrm{Cl}}=1478+19.60 \mathrm{~S}_{1+2}$ & $0.576^{*}$ \\
\hline$Y_{\mathrm{Cl}}=1199+6.34 \mathrm{~S}_{1+2+4}$ & $0.576^{*}$ \\
\hline$Y_{\mathrm{Cl}}=1228+3.03 \mathrm{~S}_{1+2+4+5}$ & 0.508 \\
\hline$Y_{\mathrm{Cl}}=1226+1.90 \mathrm{~S}_{1+2+3+4+5}$ & 0.546 \\
\hline \multicolumn{2}{|l|}{ Seed } \\
\hline$Y_{\mathrm{Cd}}=823+13.48 \mathrm{~S}_{1}$ & $0.582 *$ \\
\hline$Y_{\mathrm{Cd}}=778+7.05 \mathrm{~S}_{1+2}$ & $0.605^{*}$ \\
\hline$Y_{\mathrm{Cd}}=688+2.51 \mathrm{~S}_{1+2+4}$ & $0.599^{*}$ \\
\hline$Y_{\mathrm{Cd}}=691+0.990 \mathrm{~S}_{1+2+4+5}$ & $0.557^{*}$ \\
\hline$Y_{\mathrm{Cd}}=702+0.593 \mathrm{~S}_{1+2+3+4+5}$ & 0.542 \\
\hline
\end{tabular}

Abbreviations: as per Table 1.

* Significant at $5 \%$ level.

** Significant at $1 \%$ level.

$\mathrm{S}_{5}$ and $\mathrm{S}_{3}$ were added (Table 2). Similar situations existed for rape, though the correlations were poorer than the corresponding values for wheat. These results indicate $S_{1}, S_{2}$ and $S_{4}$ can be regarded as available forms of sulfur to wheat, while $S_{5}$ and $S_{3}$ are rarely available under the same conditions.

Results from field survey were somewhat different from pot experiments (Tables 3 and 4). In most cases the single correlations were found to be significant $(P<0.05)$, and adding $\mathrm{S}_{5}$ and $\mathrm{S}_{3}$ did not lead to marked reduction in the values of correlation coefficients. This result should be attributed to the higher multicollinearity (Table 5) among different sulfur species in the soils of field survey, which have similar properties and sulfur distribution patterns, whereas soils used for pot
Table 4

Single rcgression cquations betwecn sulfur speciation in soils and sulfur content in rice (field survey, $n=13$ )

\begin{tabular}{|c|c|}
\hline Regression equation & $r$ \\
\hline \multicolumn{2}{|l|}{ Root } \\
\hline$Y_{\mathrm{RT}}=1453+52.94 \mathrm{~S}_{1}$ & $0.665^{* * *}$ \\
\hline$Y_{\mathrm{Rr}}=1282+32.32 \mathrm{~S}_{1+2}$ & $0.662 * *$ \\
\hline$Y_{\mathrm{Rr}}=1103+8.64 \mathrm{~S}_{1+2+4}$ & $0.616^{*}$ \\
\hline$Y_{\mathrm{Rr}}=1313+2.37 \mathrm{~S}_{1+2+4+5}$ & $0.585^{*}$ \\
\hline$Y_{\mathrm{Rr}}=1590+1.16 \mathrm{~S}_{1+2+3+4+5}$ & 0.528 \\
\hline \multicolumn{2}{|l|}{ Stem } \\
\hline$Y_{\mathrm{Rs}}=541+32.03 \mathrm{~S}_{1}$ & $0.727^{* *}$ \\
\hline$Y_{\mathrm{Rs}}=444+22.9 \mathrm{~S}_{1+2}$ & $0.752^{* *}$ \\
\hline$Y_{\mathrm{Rs}}=308+6.34 \mathrm{~S}_{1+2+4}$ & $0.661^{* *}$ \\
\hline$Y_{\mathrm{Rs}}=402+2.55 \mathrm{~S}_{1+2+4+5}$ & $0.554^{*}$ \\
\hline$Y_{\mathrm{Rs}}=625+1.34 \mathrm{~S}_{1+2+3+4+5}$ & 0.526 \\
\hline \multicolumn{2}{|l|}{ Leaf } \\
\hline$Y_{\mathrm{Rl}}=1053+40.2 \mathrm{~S}_{1}$ & $0.726^{* *}$ \\
\hline$Y_{\mathrm{Rl}}=879+25.9 \mathrm{~S}_{1+2}$ & $0.732^{* *}$ \\
\hline$Y_{\mathrm{Rl}}=974+4.84 \mathrm{~S}_{1+2+4}$ & $0.639^{*}$ \\
\hline$Y_{\mathrm{Rl}}=1038+1.81 \mathrm{~S}_{1+2+4+5}$ & 0.473 \\
\hline$Y_{\mathrm{R} 1}=1252+0.80 \mathrm{~S}_{1+2+3+4+5}$ & 0.526 \\
\hline \multicolumn{2}{|l|}{ Seed } \\
\hline$Y_{\mathrm{Rd}}=921+15.54 \mathrm{~S}_{1}$ & $0.741^{* *}$ \\
\hline$Y_{\mathrm{Rd}}=843+10.1 \mathrm{~S}_{1+2}$ & $0.743^{* *}$ \\
\hline$Y_{\mathrm{Rd}}=929+1.81 \mathrm{~S}_{1+2+4}$ & $0.536^{*}$ \\
\hline$Y_{\mathrm{Rd}}=962+0.833 \mathrm{~S}_{1+2+4+5}$ & 0.386 \\
\hline$Y_{\mathrm{Rd}}=1086+0.326 S_{1+2+3+4+5}$ & 0.272 \\
\hline
\end{tabular}

Abbreviations: as per Table 1 .

* Significant at $5 \%$ level.

** Significant at $1 \%$ level.

experiments were collected from different regions of China and varied largely in chemical and physical properties as well as sulfur speciation.

The weakness of single regression analysis for assessing availability of soil sulfur is obvious. The correlations between plant sulfur and available forms of soil sulfur were not consistently significant as shown in Table 2. In particular, the availability of various sulfur fractions cannot be differentiated clearly from the result of single regression analysis, as different sulfur forms were 'tied' together to act as a single variable.

\subsubsection{Multiple regression analysis}

The relationship between plant sulfur and sulfur speciation in soils was better described by the 
Table 5

Corrclation cocfficients $(r)$ for relationship among different forms of soil sulfur

\begin{tabular}{llcccc}
\hline & \multicolumn{2}{c}{ Soils used for pot experiments } & & & \\
\cline { 2 - 6 } S form & $S_{1}$ & $S_{2}$ & $S_{3}$ & $S_{4}$ & $S_{5}$ \\
\hline$S_{1}$ & & 0.447 & 0.379 & 0.412 & 0.105 \\
$S_{2}$ & & 0.170 & 0.310 & 0.394 \\
$S_{3}$ & & & 0.253 & 0.409 \\
$S_{4}$ & & & & 0.355 \\
$S_{1}$ & Soils from field survey & $0.666^{*}$ & $0.597^{*}$ & $0.713^{* *}$ & $0.677^{*}$ \\
$S_{2}$ & & & 0.414 & $0.608^{*}$ & $0.612^{*}$ \\
$S_{3}$ & & & $0.581^{*}$ & 0.546 \\
$S_{4}$ & & & & $0.847^{* *}$ \\
\hline
\end{tabular}

Abbreviations: as per Table 1.

* Significant at $5 \%$ level.

** Significant at $1 \%$ level.

'Iable 6

Multiple regression equations between sulfur speciation in soils and sulfur content in wheat and rape (pot experiments)

\begin{tabular}{ll}
\hline Regression equation & $r$ \\
\hline Wheat & \\
$Y_{\mathrm{W}}=376+24.3 \mathrm{~S}_{1}+8.7 \mathrm{~S}_{2}$ & $0.744^{* *}$ \\
$Y_{\mathrm{W}}=163+21.0 \mathrm{~S}_{1}+5.8 \mathrm{~S}_{2}+2.2 \mathrm{~S}_{4}$ & $0.868^{* * *}$ \\
$Y_{\mathrm{W}}=139+20.2 \mathrm{~S}_{1}+5.0 \mathrm{~S}_{2}+2.08 \mathrm{~S}_{4}+0.28 \mathrm{~S}_{5}$ & $0.880^{* * *}$ \\
$Y_{\mathrm{W}}=150+24.5 \mathrm{~S}_{1}+4.50 \mathrm{~S}_{2}+1.91 \mathrm{~S}_{4}+0.26 \mathrm{~S}_{5}$ & \\
$\quad-0.17 \mathrm{~S}_{3}$ & $0.868^{* * *}$ \\
& \\
$\mathrm{Rape}$ & \\
$Y_{\mathrm{R}}=688+27.8 \mathrm{~S}_{1}+7.7 \mathrm{~S}_{2}$ & $0.728^{* *}$ \\
$Y_{\mathrm{R}}=481+22.6 \mathrm{~S}_{1}+5.5 \mathrm{~S}_{2}+2.4 \mathrm{~S}_{4}$ & $0.827^{* * *}$ \\
$Y_{\mathrm{R}}=359+21.1 \mathrm{~S}_{1}+5.0 \mathrm{~S}_{2}+2.6 \mathrm{~S}_{4}+0.37 \mathrm{~S}_{5}$ & $0.828^{* * *}$ \\
$Y_{\mathrm{R}}=362+27.4 \mathrm{~S}_{1}+5.4 \mathrm{~S}_{2}+2.4 \mathrm{~S}_{4}+0.38 \mathrm{~S}_{5}$ & \\
$\quad-0.19 \mathrm{~S}_{3}$ & $0.845^{* * *}$ \\
\hline
\end{tabular}

Abbreviations: as per Table 1.

** Significant at $1 \%$ level.

*** Significant at $0.1 \%$ level.

multiple regression model (Tables 6-8). All the correlations were found to be highly significant $(P<0.01$ or 0.001$)$. Furthermore, the regression equations showed consistent forms with respect to the relative magnitude of the factors before each of the variables, by the order $\mathrm{S}_{1}>\mathrm{S}_{2}>\mathrm{S}_{4}>$ $\mathrm{S}_{5}>\mathrm{S}_{3}$. The factor of $\mathrm{S}_{1}$ is in the range of 12.4-50.6, with the mean value of 28.6 , and the mean values of the factors of $S_{2}, S_{4}, S_{5}$ and $S_{3}$ are $11.0,3.2,0.47$ and -0.14 , respectively. Be-
Table 7

Multiple regression equations between sulfur speciation in soils and sulfur content in corn (field survey)

\begin{tabular}{|c|c|}
\hline Regression equation & $r$ \\
\hline \multicolumn{2}{|l|}{ Root } \\
\hline$Y_{C_{r}}=787+48.7 S_{1}+15.5 S_{2}$ & $0.786^{* * *}$ \\
\hline$Y_{\mathrm{CI}}=554+38.4 \mathrm{~S}_{1}+14.9 \mathrm{~S}_{2}+3.9 \mathrm{~S}_{4}$ & $0.936 * * *$ \\
\hline$Y_{\mathrm{CI}_{\mathrm{I}}}=527+39.4 \mathrm{~S}_{1}+15.0 \mathrm{~S}_{2}+3.3 \mathrm{~S}_{4}+0.27 \mathrm{~S}_{5}$ & $0.929 * * *$ \\
\hline $\begin{aligned} Y_{\mathrm{Cr}}= & 537+36.5 \mathrm{~S}_{1}+15.3 \mathrm{~S}_{2}+3.4 \mathrm{~S}_{4}+0.30 \mathrm{~S}_{5} \\
& -0.18 \mathrm{~S}_{3}\end{aligned}$ & $0.964^{* * *}$ \\
\hline
\end{tabular}

Stem

$$
\begin{aligned}
Y_{\mathrm{Cs}}= & 176+16.6 \mathrm{~S}_{1}+6.3 \mathrm{~S}_{2} \\
Y_{\mathrm{Cs}}= & 73.4+12.6 \mathrm{~S}_{1}+4.9 \mathrm{~S}_{2}+2.2 \mathrm{~S}_{4} \\
Y_{\mathrm{CS}}= & 74.8+12.5 \mathrm{~S}_{1}+4.7 \mathrm{~S}_{2}+2.0 \mathrm{~S}_{4}+0.15 \mathrm{~S}_{5} \\
Y_{\mathrm{Cs}}= & 68.3+14.4 \mathrm{~S}_{1}+4.4 \mathrm{~S}_{2}+2.0 \mathrm{~S}_{4}+0.28 \mathrm{~S}_{5} \\
& -0.08 \mathrm{~S}_{3}
\end{aligned}
$$

$0.804 * * *$

$0.958^{* * *}$

$0.964^{* * *}$

$0.965^{* * *}$

$$
\begin{aligned}
& \text { Leaf } \\
& Y_{\mathrm{Cl}}=1158+50.4 \mathrm{~S}_{1}+16.4 \mathrm{~S}_{2} \\
& Y_{\mathrm{Cl}}=668+50.6 \mathrm{~S}_{1}+16.0 \mathrm{~S}_{2}+5.8 \mathrm{~S}_{4} \\
& Y_{\mathrm{Cl}}=657+47.4 \mathrm{~S}_{1}+16.1 \mathrm{~S}_{2}+5.6 \mathrm{~S}_{4}+0.48 \mathrm{~S}_{5} \\
& Y_{\mathrm{Cl}}=602+49.7 \mathrm{~S}_{1}+14.6 \mathrm{~S}_{2}+5.4 \mathrm{~S}_{4}+0.42 \mathrm{~S}_{5} \\
& -0.09 \mathrm{~S}_{3}
\end{aligned}
$$

$0.810^{* * *}$ $0.958^{* * *}$ $0.964^{* * *}$ $0.930^{* * *}$

Seed

$$
\begin{aligned}
Y_{\mathrm{Cd}}= & 681+15.8 \mathrm{~S}_{1}+5.3 \mathrm{~S}_{2} \\
Y_{\mathrm{Cd}}= & 534+13.7 \mathrm{~S}_{1}+4.7 \mathrm{~S}_{2}+1.9 \mathrm{~S}_{4} \\
Y_{\mathrm{Cd}}= & 539+15.5 \mathrm{~S}_{1}+4.5 \mathrm{~S}_{2}+1.7 \mathrm{~S}_{4}+0.22 \mathrm{~S}_{5} \\
Y_{\mathrm{Cd}}= & 535+15.6 \mathrm{~S}_{1}+5.1 \mathrm{~S}_{2}+1.9 \mathrm{~S}_{4}+0.19 \mathrm{~S}_{5} \\
& -0.055 \mathrm{~S}_{3}
\end{aligned}
$$

$0.782 * * *$

$0.904^{* * *}$

$0.918 * * *$

$0.919^{* * *}$

Abbreviations: as per Table 1.

*** Significant at $0.1 \%$ level. 
Table 8

Multiple regression equations between sulfur speciation in soils and sulfur content in rice (field survey)

\begin{tabular}{|c|c|}
\hline Regression equation & $r$ \\
\hline $\begin{aligned} \text { Root } & \\
Y_{\mathrm{Rx}}= & 1082+40.2 \mathrm{~S}_{1}+17.5 \mathrm{~S}_{2} \\
Y_{\mathrm{Rr}}= & 725+36.1 \mathrm{~S}_{1}+15.9 \mathrm{~S}_{2}+4.2 \mathrm{~S}_{4} \\
Y_{\mathrm{Rr}}= & 596+39.4 \mathrm{~S}_{1}+16.7 \mathrm{~S}_{2}+3.8 \mathrm{~S}_{4}+0.88 \mathrm{~S}_{5} \\
Y_{\mathrm{Rr}}= & 630+38.8 \mathrm{~S}_{1}+16.2 \mathrm{~S}_{2}+4.1 \mathrm{~S}_{4}+0.65 \mathrm{~S}_{5} \\
& -0.26 \mathrm{~S}_{3}\end{aligned}$ & $\begin{array}{l}0.792^{* * * *} \\
0.895^{* * *} \\
0.912^{* * *} \\
0.920^{* * *}\end{array}$ \\
\hline $\begin{array}{l}\text { Stem } \\
\qquad \begin{aligned} Y_{\mathrm{Rs}}= & 176+33.1 \mathrm{~S}_{1}+20.6 \mathrm{~S}_{2} \\
Y_{\mathrm{Rs}}= & 86.3+32.6 \mathrm{~S}_{1}+17.8 \mathrm{~S}_{2}+3.6 \mathrm{~S}_{4} \\
Y_{\mathrm{Rs}}= & 53.8+32.1 \mathrm{~S}_{1}+16.3 \mathrm{~S}_{2}+2.4 \mathrm{~S}_{4}+1.2 \mathrm{~S}_{5} \\
Y_{\mathrm{Rs}}= & 69+32.0 \mathrm{~S}_{1}+15.7 \mathrm{~S}_{2}+2.8 \mathrm{~S}_{4}+1.1 \mathrm{~S}_{5} \\
& -0.12 \mathrm{~S}_{3}\end{aligned}\end{array}$ & $\begin{array}{l}0.825^{* * *} \\
0.946^{* * * *} \\
0.951^{* * *} \\
0.958^{* * *}\end{array}$ \\
\hline $\begin{array}{l}\text { Leaf } \\
\qquad \begin{aligned} Y_{\mathrm{Rl}}= & 788+36.9 \mathrm{~S}_{1}+18.4 \mathrm{~S}_{2} \\
Y_{\mathrm{Rl}}= & 573+29.5 \mathrm{~S}_{1}+15.8 \mathrm{~S}_{2}+4.2 \mathrm{~S}_{4} \\
Y_{\mathrm{Rl}}= & 476+28.8 \mathrm{~S}_{1}+14.9 \mathrm{~S}_{2}+4.1 \mathrm{~S}_{4}+0.68 \mathrm{~S}_{5} \\
Y_{\mathrm{Rl}}= & 458+28.8 \mathrm{~S}_{1}+14.4 \mathrm{~S}_{2}+4.4 \mathrm{~S}_{4}+0.73 \mathrm{~S}_{5} \\
& -0.10 \mathrm{~S}_{3}\end{aligned}\end{array}$ & $\begin{array}{l}0.732^{* *} \\
0.949^{* * *} \\
0.957^{* * * *} \\
0.957^{* * * *}\end{array}$ \\
\hline $\begin{aligned} \text { Seed } & \\
Y_{\mathrm{Rd}}= & 770+18.4 \mathrm{~S}_{1}+7.1 \mathrm{~S}_{2} \\
Y_{\mathrm{Rd}}= & 604+17.5 \mathrm{~S}_{1}+7.9 \mathrm{~S}_{2}+3.3 \mathrm{~S}_{4} \\
Y_{\mathrm{Rd}}= & 585+16.2 \mathrm{~S}_{1}+8.5 \mathrm{~S}_{2}+2.7 \mathrm{~S}_{4}+0.29 \mathrm{~S}_{5} \\
Y_{\mathrm{Rd}}= & 529+18.3 \mathrm{~S}_{1}+7.3 \mathrm{~S}_{2}+3.0 \mathrm{~S}_{4}+0.30 \mathrm{~S}_{5} \\
& -0.16 \mathrm{~S}_{3}\end{aligned}$ & $\begin{array}{l}0.744^{* *} \\
0.944^{* * *} \\
0.950^{* * *} \\
0.957^{* * *}\end{array}$ \\
\hline
\end{tabular}

Abbreviations: as per Table 1.

** Significant at $1 \%$ level.

*** Significant at $0.1 \%$ level.

cause the factor before a variable is directly related to the contribution of the sulfur fraction to plant uptake of sulfur, the availability of different sulfur forms can be evaluated. Water-soluble sulfate is believed to be directly available to plants (Ensminger and Freney, 1966) and accordingly, it is the most easily available form of sulfur followed by adsorbed sulfate, which is in chemical equilibrium with water-soluble sulfate and serves as a rapid reserve of soluble sulfate once it is depleted. The estimation that soil organic sulfur may be an important pool of plant-available sulfur was confirmed in this study. Ester sulfate proved to be more available than carbon-bonded sulfur as evidenced by the larger factor of $S_{4}$ than that of $S_{5}$, supported by the fact that the mineral- ization of sulfate from ester sulfate is more rapid than from carbon-bonded sulfur (Maynard et al., 1985; McLaren et al., 1985; Blair et al., 1994). Nevertheless, carbonate-occluded sulfate appeared to exert a negative effect on plant uptake of soil sulfur since the factor before $\mathrm{S}_{3}$ is negative. The reason may lie in the fact that high content of $\mathrm{S}_{3}$ generally means high content of carbonates in soils and high pH level of soil. Under these conditions the activity of most cations and anions in soils are lowered due to the formation of many metal precipitates and co-precipitates, such as gypsum, anhydrite, celestite as well as basic $\mathrm{Fe}$ and $\mathrm{Al}$ sulphates (Wedepohl, 1978).

The multiple regression equations which contain only $S_{1}$ and $S_{2}$ did not correlate with plant sulfur as well as the equations including three or more sulfur forms. Adding $\mathrm{S}_{4}$ improved the correlation markedly. However, the effect of adding $S_{5}$ and $S_{3}$ was not significant. This indicates $S_{1}, S_{2}$ and $S_{4}$ covered most of the available sulfur in soils on a short-term basis. The correlations for field survey were better than that for pot experiments for the same kind of regression analysis. The reason should be similar to that given to single regression analysis. The possibility also exists that mineralization of soil organic sulfur will become more important if the growth period is prolonged as in the case of crop growth in the field, leading to more significant correlations with organic sulfur in field survey.

Direct evidence was obtained from the percent changes of the various forms of soil sulfur after pot experiments (Fig. 2) for understanding the availability of these sulfur forms. $\mathrm{S}_{1}$ decreased most rapidly ( $30.2 \%$ for wheat and $38 \%$ for rape, average value of the 13 soils), followed by $S_{2}(12.5$ and $14 \%)$ and $\mathrm{S}_{4}(4.8$ and $5.5 \%)$, whereas $\mathrm{S}_{5}$ and $\mathrm{S}_{3}$ remained almost unchanged. Morenver, the reductions of soil sulfur accounted for $91 \%$ and $85 \%$ of total sulfur uptake into the shoots of wheat and rape, respectively, while the changes of $S_{1}$ and $S_{2}$ only made up 50 and $43 \%$ of total sulfur in the shoots, indicating more than $40 \%$ of shoot sulfur came from an organic source. The plant sulfur unaccounted for by soil sulfur changes may be derived directly from atmospheric sulfur 


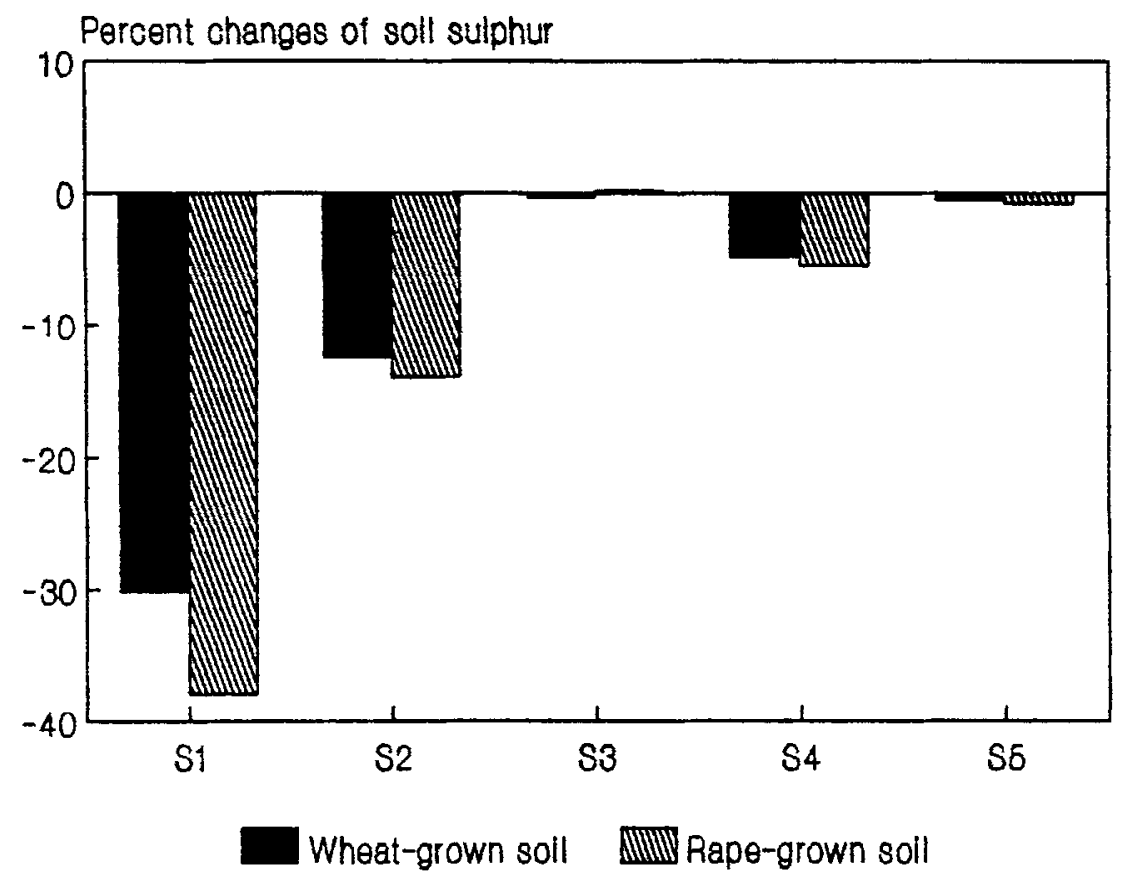

Fig. 2. Percent changes of various sulfur forms after pot experiments (average value of the 13 soils).

(Zhao and McGrath, 1994). The significant reduction of water-soluble and adsorbed sulfate during the period of pot experiments suggested that soils are very likely to evolve sulfur-deficiency under intensive crop growth without sufficient sulfur input from the atmosphere and fertilizers (Morris, 1988; Kjellquist and Gruvaeus, 1995; Zhao et al., 1995).

\subsection{Simplified sulfur speciation method in soils}

It is clear that the single extractions with weak salt solutions for soil testing only covered soluble sulfate, adsorbed sulfate and a minor fraction of soil organic sulfur and did not give a full cstimation of the capacity of soil to supply plant available sulfur (Freney et al., 1975). However, the multiple regression equations containing watersoluble sulfate, adsorbed sulfate and ester sulfate gave excellent correlations with plant sulfur for both pot experiments and field survey. It appears that the sum of the three forms of sulfur could account for most of the available sulfur in soils and can be used as an indicator of the status of soil sulfur. Using plant availability as a criterion, the tedious sulfur speciation procedure can be simplified. The unavailable or hardly-available forms of soil sulfur such as carbon-bonded sulfur

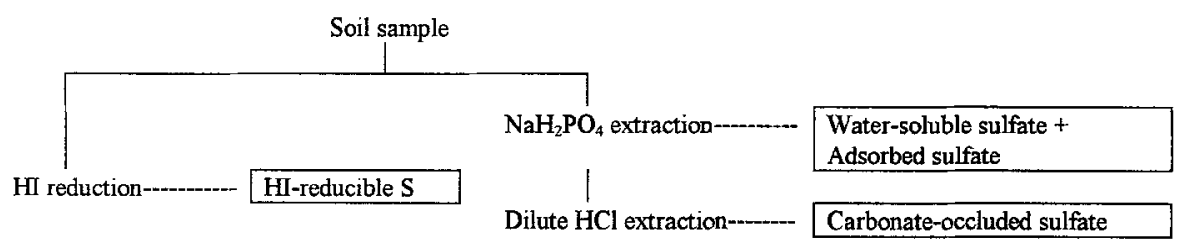

Available $\mathrm{S}=$ Water-soluble sulfate + Adsorbed sulfate + Ester sulfate

$=$ HI-reducible $\mathrm{S}$ - Carbonate-occluded sulfate

Fig. 3. Simplified procedure for the determination of available sulfur in soils containing little or no reduced forms of sulfur. 
need not be determined. On the other hand, most agricultural soils contain little amounts of reduced forms of sulfur. Therefore, the simplified speciation method was suggested to determine the sum of water-soluble, adsorbed and ester sulfate, as shown in Fig. 3. Water-soluble and adsorbed sulfate can be recovered by $\mathrm{NaH}_{2} \mathrm{PO}_{4}$ extraction. The $\mathrm{H}_{2} \mathrm{O}_{2}$ oxidation and $\mathrm{H}_{2} \mathrm{O}$ extraction in Fig. 1 are omitted.

\section{Acknowledgements}

This work was funded by the National Natural Science Foundation of China.

\section{References}

Anderson, G., Lefroy, R., Chinoim, N. and Blair, G. (1992) Soil sulfur testing. Sulfur and Agric. 16, 6-14.

Blair, G.J., Till, A.R. and Shedley, C.D. (1994) Transformations of sulfur in soil and subsequent uptake by subterranean clover. Aus. J. Soil Res. 32, 1207-1214.

Chen, B. and Shan, X.O. Nature of the HCl-soluble sulphate in the sequential extraction for sulfur speciation in soils. Fresenius J. Anal. Chem. (Submitted).

David, M.B., Schindler, S.C., Mitchell, M.J. and Strick, J.E. (1983) Importance of organic and inorganic sulfur to mineralization processes in a forest soil. Soil Bio. Biochem. 15 , 671-677.

Ensminger, L.E. and Freney, J.R. (1966) Diagnostic techniques for determination sulfur deficiencies in crops and soils. Soil Sci. 101, 283-290.

Fox, R.L., Olson, R.A. and Rhoades, H.F. (1964) Evaluating the sulfur status of soil by plant and soil tests. Soil Sci. Soc. Am. Proc. 28, 243- 246.

Freney, J.R., Melville, G.E. and Williams, C.H. (1975) Soil organic matter fractions as sources of plant-available sulfur. Soil Bio. Biochem. 7, 217-221.

Haneklaus, S., Fleckenstein, J. and Schnug, E. (1995) Comparative studies of plant and soil analysis for the sulfur status of oilseed rape and winter wheat. Z. Pflanzenernaehr. Bodenkd. 158, 109-111.

Hoque, S., Heath, S.B. and Killham, K. (1987) Evaluation of methods to assess adequacy of potential soil $S$ supply to crops. Plant Soil 101, 3-8.

Johnson, D.W. and Todd, D.E. (1983) Relationships among iron, aluminium, carbon and sulfate in a variety of forest soils. Soil Sci. Soc. Am. J. 17, 192-500.

Jones, L.H.P., Cowling, D.W. and Lockyer, D.R. (1972) Plant available and extractable sulfur in some soils of England and Wales. Soil Sci. 114, 104-114.

Kjellquist, T. and Gruvaeus, I. (1995) Sulfur deficiency in oilseed rape and cereals - experience from Swedish field trials. Z. Pflanzenernaehr. Bodenkd. 158, 101-103.
Landerst, D.H., David, M.B. and Mitchell, M.J. (1983) Analysis of organic and inorganic sulfur constituents in sediments, soils and water. Int. J. Env. Analyt. Chem. 14, 245-256.

Maynard, D.G., Stewart, J.W. and Bettany, J.R. (1985) The effects of plants on soil sulfur transformation. Soil Biol. Biochem. 17, 127-134.

McLaren, R.G., Keer, J.I. and Swift, R.S. (1985) Sulfur transformations in soils using sulfur-35 labelling. Soil Biol. Biochem. 17, 73-79.

Morris, R.J. (1988) Sulfur - the fourth major plant nutrient. In: Jae-Sung Shin (editor), Proceedings of International Symposium on Sulfur for Korean Agriculture. Seoul, Korea, May 5-7, 1988, Korean Society of Soil Science and Fertilizer/The Sulfur Institute, Washington DC, pp. 9-16.

N'dayegamiye, A., Simard, R.R. and Delisle, F. (1994) Evaluation of sulfur mineralization potential of meadow soils and availability to alfalfa. Can. J. Soil Sci. 74, 259-265.

Nriagu, J.O. and Soon, Y.K. (1985) Distribution and isotopic composition of sulfur in lake sediments of northern Ontario. Geochim. Cosmochim. Acta 49, 823-834.

Qian, J., Wang, Z.J., Shan, X.Q., Tu, Q., Wen, B. and Chen, B. (1995) Evaluation of plant availability of soil trace metals by chemical fractionation and multiple regression analysis. Environ. Poll. 91, 309-315.

Randall, G.W., Schulte, E.E. and Corey, R.B. (1976) Correlation of plant manganese with extractable soil manganese and soil factors. Soil Sci. Soc. Am. J. 40, 282-287.

Scott, N.M. (1981) Evaluation of sulfate status of soils by plant and soil tests. J. Sci. Food Agric. 32, 203-212.

Shan, X.Q., Chen, B., Jin, L.Z., Zheng, Y., Hou, X.P. and Mou, S.F. (1992) Determination of sulfur fractions in soils by sequential extraction, inductively coupled plasma-optical emission spectroscopy and ion chromatography. Chem. Speciation Bioavail, 4, 97-103.

Shan, X.Q. and Chen, B. (1995) Determination of carbonbonded sulfur in soils by hydriodic acid reduction and hydrogen peroxide oxidation. Fresenius J. Anal. Chem. 351, $762-767$.

Stanko-Golden, K.M., Swank, W.T. and Fitzgerald, J.W. (1994) Factors affecting sulfate adsorption, organic sulfur formation, and mobilization in forest and grassland spodosols. Biol. Fertil. Soils 17, 289-296.

Tan, Z., McLaren, R.G. and Cameron, K.C. (1994) Forms of sulfur extracted from soils after different methods of sample preparation. Aus. J. Soil Res. 32, 823-834.

Wedepohl, K.H. (1978) Sulfur in Handbook of Geochemistry. Springer-Verlag, Berlin, Heidelberg, New York.

Zhao, F. and McGrath, S.P. (1994) Extractable sulfate and organic sulfur in soils and their availability to plants. Plant Soil $164,243-250$.

Zhao, F., McGrath, S.P., Crossland, A.R. and Salmon, S.E. (1995) Changes in the sulfur status of British wheat grain in the last decade, and its geographical distribution. J. Sci. Food Agric. 68, 507-514 